\title{
Sensitive ultra-fast liquid chromatography method for rosmarinic acid determination in Wistar rat's plasma and brain
}

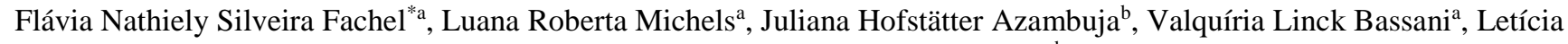 \\ Scherer Koester ${ }^{\mathrm{a}}$, Amelia Teresinha Henriques ${ }^{\mathrm{a}}$, Elizandra Braganhol ${ }^{\mathrm{b}}$, Helder Ferreira Teixeira ${ }^{\mathrm{a}}$ \\ a Programa de Pós-Graduação em Ciências Farmacêuticas, Faculdade de Farmácia, Universidade Federal do Rio Grande do \\ Sul (UFRGS), Porto Alegre, RS, Brazil; ${ }^{b}$ Programa de Pós-Graduação em Biociências, Universidade Federal de Ciências da \\ Saúde de Porto Alegre (UFCSPA), Porto Alegre, RS, Brazil.
}

*Corresponding author: flavia_fachel@hotmail.com

\begin{abstract}
Rosmarinic acid (RA) is a polyphenolic compound recently associated to a neuroprotective potential. Nevertheless, besides the RA poor bioavailability and availability in the central nervous system (CNS) some alternatives to RA delivery, protection, and release been investigated. Recently, our research group optimized chitosan-coated nanoemulsions for RA nasal administration and demonstrated the glioprotective effect against LPS-induced damage in astrocytes. In this context, this study aimed to validate a fast and simplified UFLC method previously reported by our research group for RA determination in Wistar rat's plasma and brain, to be employed in further in vivo studies, since the nasal route for RA are not completely understood. The method was validated in terms of specificity, linearity, matrix effect, stability, precision, accuracy and extraction recovery for rat plasma and brain, according to the official guidelines. The method was sensitive, linear $\left(0.1-10.0 \mu \mathrm{g} \cdot \mathrm{mL}^{-1}\right)$, precise and accurate, and showed RA recovery higher than $85 \%$ in plasma and brain. Overall results demonstrated that method was successfully validated for determination of RA in rat plasma and brain matrices with high sensibility and with high recovery using simple extraction processes.
\end{abstract}

Keywords: Rosmarinic acid; UFLC method; plasma; brain; Wistar rats.

\section{Introduction}

Rosmarinic acid (RA) is a polyphenolic compound (Fig.1), an ester of caffeic acid and 3,4-dihydroxyphenyllactic acid. It has numerous biological activities, including a current welldocumented anti-inflammatory and antioxidant activities recently associated to a neuroprotective potential [1-6]. Nevertheless, besides the RA poor bioavailability and availability in the central nervous system (CNS), in view of its limited ability to cross the blood-brain barrier (BBB), some alternatives to RA delivery, protection, and release been investigated intended to be used as a new neuroprotective therapy $[1,7,8]$.

Nasal route has been emerged as an alternative strategy for drugs delivery directly to CNS, owing to its ability to by passing $\mathrm{BBB}$, an important obstacle for the delivery of therapeutic agents [9]. In this way, our research group optimized chitosan-coated nanoemulsions for RA nasal administration, since we have recognised that the association of lipid nanotechnology-based delivery systems with mucoadhesive polymers have been a promising approach to improve RA penetration through biological barriers and its residence time in nasal cavity [10]. Additionally, we have recently demonstrated the glioprotective effect against LPSinduced damage in rat astrocyte primary cultures [11].

However, further in vivo studies to evaluate this promising neuroprotective approach are still crucial. In this context, this study aimed to validate a fast and simplified ultra-fast liquid chromatography (UFLC) method previously developed by our research group [12] for RA determination in Wistar rat's plasma and brain, to be employed in further in vivo studies, since the nasal route for RA are not completely understood.

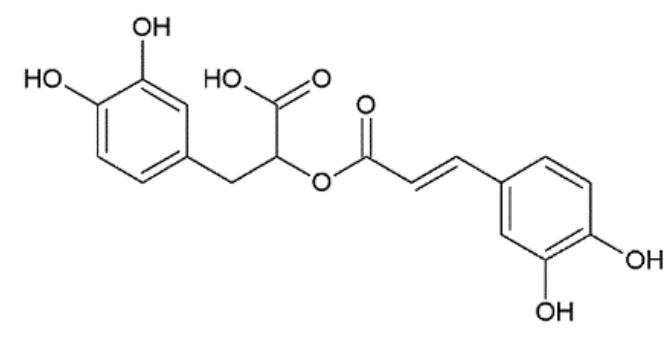

Figure 1. Rosmarinic acid (RA) chemical structure.

\section{Experimental}

\section{Chemicals and reagents}

RA reference standard with over $98 \%$ purity was acquired from Carbosynth Ltd. (Berkshire, GB). Acetonitrile, methanol, and trifluoracetic acid liquid chromatographic grade were purchased from Tedia (Rio de Janeiro, BR). Reverse osmosis using a Milli-Q apparatus (Millipore, Billerica, US) was employed to obtain ultra-pure water.

\section{Instrumentation and chromatographic conditions}

UFLC Shimadzu Prominence series system equipped with an automatic injector, a photodiode array (PDA) detector and an LC solutions software (Kyoto, Japan) was employed for RA analyses. Kinetex C18 column (100 x $2.1 \mathrm{~mm}$ i.d.; particle size, $2.6 \mu \mathrm{m}$; Phenomenex, USA) guarded by a pre-column filter in-line Ultra (Phenomenex, USA) was employed for chromatographic separation at $55^{\circ} \mathrm{C}$, flow rate of 0.55 mL.min ${ }^{-1}$, injection volume of $3 \mu \mathrm{L}$ and detection wavelength of $330 \mathrm{~nm}$. An isocratic eluent composed of water and acetonitrile $(83: 17, \mathrm{v} / \mathrm{v})$, acidified with $0.1 \%$ trifluoracetic acid (v/v), was employed up to $3.5 \mathrm{~min}$ [12]. 


\section{Standard and matrices solutions preparation}

\section{$R A$ standard}

A stock solution of RA (1.0 mg. $\left.\mathrm{mL}^{-1}\right)$ was prepared in methanol. The stock solution was then diluted in water/acetonitrile mixture $(80: 20 ; \mathrm{v}: \mathrm{v})$ to obtain a series of working standard solutions. The stock and standard solution were maintained in darkness at $4 \pm 2{ }^{\circ} \mathrm{C}$.

\section{Rat plasma and brain matrices}

Plasma matrix from Wistar rats was prepared by proteins precipitation using trichloroacetic acid 5\% (w/v). Plasma homogenates were centrifuged $(1,000 \mathrm{~g}, 10 \mathrm{~min})$, the supernatants were collected, diluted 1:1 in water:acetonitrile mixture (80:20; v:v) and filtered through a $0.22 \mu \mathrm{m}$ nylon syringes filter.

Brain matrix from Wistar rats was obtained by homogenization of tissue with methanol ( $3 \mathrm{~mL}$ per $\mathrm{g}$ of tissue) and further sonication in ultrasonic bath for $30 \mathrm{~min}$. Brain homogenates were centrifuged $(1,000 \mathrm{~g}, 10 \mathrm{~min})$, the supernatants were collected and filtered through a $0.22 \mu \mathrm{m}$ nylon syringes filter.

\section{Method validation}

The UFLC method previously reported by our research group [12] was validated in terms of specificity, linearity, matrix effect, stability, precision, accuracy and extraction recovery for rat plasma and brain, according to the official guidelines [13-15].

\section{System suitability}

Before method validation, system suitability parameters (peak area, retention time, theoretical plates and tailing factor of RA) were achieved to verify the appropriateness of the chromatographic system for the proposed analysis [16].

\section{Specificity}

The specificity was obtained by comparing chromatograms (peak purity and retention time) of pure RA standard solution with chromatograms of matrices (plasma and brain) spiked with RA at the concentration of $10 \mu \mathrm{g} \cdot \mathrm{mL}^{-1}$ and matrices solutions (blank samples).

\section{Linearity, matrix effect and stability}

The linearity was determined by regression analysis using the least square method. Three standard curves were obtained in three consecutive days by plotting the measured peak area versus the RA concentration in standard and matrices $(0.1$, $2.0,4.0,6.0,8.0$, and $10.0 \mu \mathrm{g} . \mathrm{mL}^{-1}$ ), by six replicates per concentration. Analysis of variance (ANOVA) were used to analyse the results using a significance level of $\alpha=0.05$.

The matrix effect of plasma and brain was evaluated by the comparison of RA-spiked matrices standard curve slopes obtained during the linearity assay with pure RA standard curve slope.

The stability of RA standard and RA-spiked matrices was assessed by performing the analysis of peak area and detecting any alteration in the chromatographic pattern of the stored samples (room temperature $=25 \pm 1{ }^{\circ} \mathrm{C}$ ) for $24 \mathrm{~h}$ compared with a freshly prepared sample, intending to overestimate the time expended during routine analysis.

\section{Precision and accuracy}

The precision was evaluated as both intra-day precision (repeatability) and inter-day precision (intermediate precision) expressed as the relative standard deviations (\% RSD) at four RA different levels $\left(0.1,2.0,6.0,10.0 \mu \mathrm{g} . \mathrm{mL}^{-1}\right)$, in six replicates at each level.

The accuracy was evaluated by adding known amounts of the RA standard at four different levels $(0.1,2.0,6.0,10.0$ $\mu \mathrm{g} . \mathrm{mL}^{-1}$ ), in six replicates at each level, and was determined as follows: $\mathrm{AC} \%=($ mean experimental concentration $\mathrm{x} 100 /$ mean theoretical concentration).

\section{Extraction recovery}

The RA extraction recovery was evaluated from Wistar rats plasma and brain spiked with known amounts of RA standard leading to a theoretical concentration of $0.1,2.0,6.0$ and 10.0 $\mu \mathrm{g} . \mathrm{mL}^{-1}$. To plasma matrices trichloroacetic acid $5 \%(\mathrm{w} / \mathrm{v})$ in proportion 1:1 (v:v) was added. Then, plasma homogenates were centrifugated $(1,000 \mathrm{~g}, 10 \mathrm{~min})$, the supernatants were collected and diluted in water/acetonitrile mixture (80:20; $\mathrm{v}: \mathrm{v})$. Brain tissues (previously washed with saline) were homogenized with $2 \mathrm{~mL}$ of methanol per $\mathrm{g}$ of tissue in an IKA $^{\circledR}$ Ultra-Turrax T8 mixer (IKA Works Inc., Wilmington, US). All matrices were filtered through a $0.22 \mu \mathrm{m}$ nylon syringes filter and analyzed by UFLC method. The recovery was expressed as percentage, assessed by comparing the theoretical final concentration based on the spiked amount and the experimental result attained after extraction procedure.

\section{Ethical committee approval}

All animal procedures were conducted with prior approval from the ethical approval of Federal University of Health Sciences of Porto Alegre, Brazil (Protocol 220/2017) and in accordance with the Brazilian Guidelines for the Care and Use of Animals in Scientific Research Activities (DBCA) and the National Council of Control of Animal Experimentation (CONCEA).

\section{Results and Discussion}

\section{Method validation}

Different methodologies for RA quantification through liquid chromatography techniques has been reported in literature [17-29]. Nevertheless, most of these methodologies focus on RA analysis in plant extracts and involves time consuming/ gradient eluent systems. In this context, recently our research group develop a fast and simplified UFLC method [12] for RA analysis based on its capability to promote ultra-highspeed analysis with shorter runtimes in comparison with previous literature, high precision and sensibility.

The UFLC method was the first report for RA determination in nanoemulsions, and porcine skin and nasal mucosa retention/permeation assay. In the literature, only few studies around validation of bioanalytical methods for biological matrices were found for RA determination, although, none of 
them included rat plasma and brain under the same experimental conditions [22,30-32].

Regarding the system suitability, overall results demonstrated that the UFLC method is suitable for RA analysis in rat plasma and brain [16]. The parameters values and their relative standard deviation (RSD, \%) were: retention time of $2.63(0.05) \mathrm{min}$, theoretical plates of $5446.82(0.08)$, and tailing factor of $1.25(0.06)$.

The method was specific for RA determination in rat plasma and brain matrices, once the RA peak purity was demonstrated in RA spiked-matrices and no co-eluting substances in the same RA retention time were detected in matrices (Fig. 2).

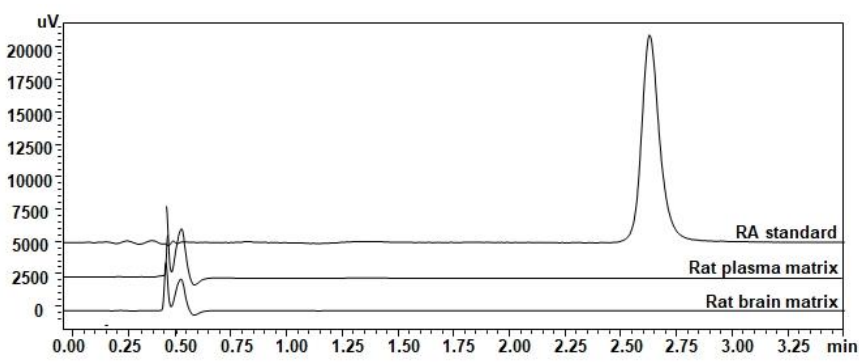

Figure 2. RA chromatographic profile standard at $10 \mu \mathrm{g} \cdot \mathrm{mL}^{-1}$ and specificity in blank samples of rat plasma and brain. RA: rosmarinic acid.

As presented in Table 1, the method was linear for RA determination in rat plasma and brain matrices in range of 0.1-1.0 $\mu \mathrm{g} . \mathrm{mL}^{-1}$ according with correlation coefficients. Linear regression and the absence of linearity deviation were also demonstrated by ANOVA evaluation of regression significance and confidence interval on the intercepts. LOQ was fixed at $0.1 \mu \mathrm{g} . \mathrm{mL}^{-1}$ as it was the lowest concentration of RA that could be quantified with acceptable precision and accuracy.

The results for rat plasma and brain matrices effects (Table 1) were lower than $2.7 \%$ and indicates a low matrix effect in RA analysis [12,33]. The matrix effect is a very important parameter in biological samples to ensure the RA correct quantification in presence of matrices [34,35].

The results obtained for intra and inter-day precision, accuracy and stability in standard and rat plasma and brain matrices are shown in Table 2. Four different concentrations of RA standard and spiked-matrices were evaluated: 0.1 $\mu \mathrm{g} . \mathrm{mL}^{-1}$ (LOQ), $2.0 \mu \mathrm{g} \cdot \mathrm{mL}^{-1}$ (lowest concentration), 6.0 $\mu \mathrm{g} \cdot \mathrm{mL}^{-1}$ (medium concentration), and $10.0 \mu \mathrm{g} \cdot \mathrm{mL}^{-1}$ (highest concentration) for each sample. The method was considered precise and accurate for RA determination in rat plasma and brain matrices according to official guidelines [13-15]. The intra-day and inter-day precision results demonstrated a relative standard deviation (RSD, \%) lower than 5\%. The accuracy ranged within 104.69 to $110.99 \%$ range. The stability data also demonstrated that the RA concentration remained constant in matrices even after $24 \mathrm{~h}$ of storage (room temperature $=25 \pm 1^{\circ} \mathrm{C}$ ).
Table 1. Linearity and summary of the output of the ANOVA of RA standard, rat plasma brain matrices.

\begin{tabular}{|c|c|c|c|c|}
\hline & & RA standard & $\begin{array}{c}\text { Rat plasma } \\
\text { matrix }\end{array}$ & $\begin{array}{c}\text { Rat brain } \\
\text { matrix }\end{array}$ \\
\hline \multirow[b]{5}{*}{ 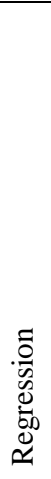 } & $\begin{array}{l}\text { Range } \\
\left(\mu \mathrm{g} \cdot \mathrm{mL}^{-1}\right)\end{array}$ & $0.1-10.0$ & $0.1-10.0$ & $0.1-10.0$ \\
\hline & $\begin{array}{l}\text { Regression } \\
\text { equation }\end{array}$ & $\begin{array}{c}y=8592 x- \\
183.18\end{array}$ & $\begin{array}{c}y=8777.8 x- \\
238.3\end{array}$ & $\begin{array}{c}y=8829.7 x \\
-40.559\end{array}$ \\
\hline & $\mathrm{R}$ & 0.9996 & 0.9994 & 0.9996 \\
\hline & $\begin{array}{l}\text { Matrix effect } \\
(\%)\end{array}$ & - & 2.12 & 2.69 \\
\hline & Significance F & $2.239 \mathrm{E}-94^{\mathrm{a}}$ & $6.376 \mathrm{E}-90^{\mathrm{a}}$ & $1.851 \mathrm{E}-97^{\mathrm{a}}$ \\
\hline \multirow{3}{*}{$\begin{array}{l}\overrightarrow{0} \\
\stackrel{0}{0} \\
\stackrel{0}{\Xi}\end{array}$} & $\mathrm{p}$-value & $0.32600^{\mathrm{b}}$ & $0.2865^{b}$ & $0.8226^{b}$ \\
\hline & Lower 95\% & -556.1767 & -693.4420 & -377.8245 \\
\hline & Upper $95 \%$ & 187.8070 & 208.5224 & 301.3503 \\
\hline
\end{tabular}

a $95 \%$ confidence level= significant linear regression; b $95 \%$ confidence level $=$ no significant linearity deviation; RA: rosmarinic acid; R: correlation coefficient.

Table 2. Intraday and intra-day precision, accuracy and stability evaluation of RA standard, rat plasma brain matrices.

\begin{tabular}{|c|c|c|c|c|c|c|c|}
\hline & \multirow{2}{*}{$\begin{array}{r}\text { Level } \\
(\mu \mathrm{g} / \mathrm{mL})\end{array}$} & \multicolumn{4}{|c|}{ Precision (RSD) } & \multirow{2}{*}{$\begin{array}{c}\text { Accuracy } \\
(\%)\end{array}$} & \multirow{2}{*}{$\begin{array}{l}\text { SE } \\
(\%)\end{array}$} \\
\hline & & $\begin{array}{l}\text { First } \\
\text { day }{ }^{a}\end{array}$ & $\begin{array}{c}\text { Second } \\
\text { day a }\end{array}$ & $\begin{array}{l}\text { Third } \\
\text { day a }\end{array}$ & $\begin{array}{c}\text { Inter- } \\
\text { day }\end{array}$ & & \\
\hline \multirow{4}{*}{ RA } & 0.1 & 3.99 & 3.99 & 3.99 & 3.51 & 105.53 & 104.69 \\
\hline & 2.0 & 4.11 & 1.38 & 2.68 & 3.31 & 97.01 & 95.58 \\
\hline & 6.0 & 1.38 & 0.21 & 0.33 & 1.06 & 101.24 & 102.37 \\
\hline & 10.0 & 0.72 & 0.67 & 0.44 & 0.77 & 98.76 & 99.41 \\
\hline \multirow{4}{*}{$\begin{array}{c}\text { Rat } \\
\text { plasma } \\
\text { matrix }\end{array}$} & 0.1 & 1.34 & 2.54 & 2.18 & 4.36 & 108.94 & 110.99 \\
\hline & 2.0 & 0.82 & 2.24 & 2.16 & 2.40 & 96.63 & 95.68 \\
\hline & 6.0 & 1.37 & 1.03 & 1.26 & 1.56 & 101.34 & 99.94 \\
\hline & 10.0 & 0.47 & 0.45 & 0.39 & 0.53 & 99.01 & 100.25 \\
\hline \multirow{4}{*}{$\begin{array}{c}\text { Rat } \\
\text { brain } \\
\text { matrix }\end{array}$} & 0.1 & 4.88 & 1.10 & 2.44 & 3.81 & 91.97 & 90.44 \\
\hline & 2.0 & 1.80 & 2.99 & 1.55 & 2.90 & 98.86 & 96.85 \\
\hline & 6.0 & 1.25 & 2.38 & 1.72 & 2.01 & 100.38 & 99.91 \\
\hline & 10.0 & 0.26 & 0.88 & 0.55 & 0.68 & 99.24 & 99.21 \\
\hline
\end{tabular}

${ }^{\mathrm{a}}$ six replicates per day; SE: stability evaluation in 24 hours; RSD= relative standard deviation (\%); RA: rosmarinic acid.

The results for RA extraction recovery from rat plasma and brain recovery are presented in Table 3 and were established after preliminary studies. The recovery was higher than $84.9 \%$ and lower than $105.1 \%$, without interference of matrix components and with adequate precision RSD lower than $11.5 \%$ for both matrices in accordance with FDA recommendations for bioanalytical procedures validation [15]. 
Table 3. RA extraction recovery from rat plasma and brain matrices.

\begin{tabular}{ccc}
\hline & Level $\left(\boldsymbol{\mu g . m L ^ { - 1 } )}\right.$ & Recovery $(\mathbf{R S D}, \boldsymbol{\%})$ \\
\hline Rat plasma & 0.1 & $84.91(11.5)$ \\
matrix & 2.0 & $89.39(4.9)$ \\
& 6.0 & $88.18(1.3)$ \\
& 10.0 & $90.49(14.9)$ \\
Rat brain & 0.1 & \\
matrix & 2.0 & $93.72(5.5)$ \\
& 6.0 & $97.82(11.5)$ \\
& 10.0 & $105.07(2.8)$ \\
\hline
\end{tabular}

RSD: relative standard deviation (\%); RA: rosmarinic acid.

\section{Conclusions}

In present study, a fast and simple UFLC method previously reported by our research group was successfully validated for determination of RA in rat plasma and brain matrices with high sensibility and with high recovery using simple extraction processes. This is the first high-throughput liquid chromatography method validated for RA determination in different complex matrices, allowing its use in further in vivo studies.

\section{Acknowledgments}

The authors are gratefully acknowledged to Conselho Nacional de Desenvolvimento científico e Tecnológico (CNPq - processos 459619/2014-4; 310846/2014-5; 422298/2016-6), Fundação de Amparo à Pesquisa do Estado do Rio Grande do Sul (FAPERGS - processos 16/25510000265-7; 16/2551-0000473-0; 17/2551-0001273-9), and Coordenação de Aperfeiçoamento de Pessoal de Nível Superior - Brasil (CAPES - Finance Code 001) for the financial grants. F.N.S.F., J.H.A. and L.R.M. would like to thank CAPES and CNPq (GD\#142202/2018-5) for the doctoral grant. V.L.B., L.S.K., A.T.H., E.B., and H.F.T. are recipients of $\mathrm{CNPq}$ research fellowship.

\section{Conflict of interest}

The authors declare no conflicts of interest.

\section{References}

1. Fachel FNS;Schuh RS;Veras KS;Bassani VL;Koester LS;Henriques AT; et al. An overview of the neuroprotective potential of rosmarinic acid and its association with nanotechnology-based delivery systems: A novel approach to treating neurodegenerative disorders. Neurochem Int, 2019,122,47-58.

2. Petersen M;Simmonds MSJ. Rosmarinic acid. Phytochemistry, 2003,62,121-5.

3. Soobrattee M a.;Neergheen VS;Luximon-Ramma a.;Aruoma OI;Bahorun T. Phenolics as potential antioxidant therapeutic agents: Mechanism and actions. Mutat Res - Fundam Mol Mech Mutagen, 2005,579,20013.
4. Bhatt R;Mishra N;Bansal PK. Phytochemical, Pharmacological and pharmacokinetics effects of rosmarinic acid. J Pharm Sci Innov, 2013,2,28-34.

5. Petersen M;Abdullah Y;Benner J;Eberle D;Gehlen $\mathrm{K}$;Hücherig $\mathrm{S}$;et al. Evolution of rosmarinic acid biosynthesis. Phytochemistry, 2009.

6. Kim G-D;Park YS;Jin Y-H;Park C-S. Production and applications of rosmarinic acid and structurally related compounds. Appl Microbiol Biotechnol, 2015,99,208392.

7. Baba S;Osakabe N;Natsume M;Terao J. Orally administered rosmarinic acid is present as the conjugated and/or methylated forms in plasma, and is degraded and metabolized to conjugated forms of caffeic acid, ferulic acid and m-coumaric acid. Life Sci, 2004,75,165-78.

8. Li S;Xie X;Li D;Yu Z;Tong L;Zhao Y. Simultaneous determination and tissue distribution studies of four phenolic acids in rat tissue by UFLC-MS/MS after intravenous administration of salvianolic acid for injection. Biomed Chromatogr, 2018,32,1-9.

9. Lochhead JJ;Thorne RG. Intranasal delivery of biologics to the central nervous system. Adv Drug Deliv Rev, 2012,64,614-28.

10. Fachel FNS;Medeiros-Neves B;Dal Prá M;Schuh RS;Veras KS;Bassani VL;et al. Box-Behnken design optimization of mucoadhesive chitosan-coated nanoemulsions for rosmarinic acid nasal delivery-In vitro studies. Carbohydr Polym, 2018,199,572-82.

11. Fachel FNS;Dal Prá M;Azambuja JH;Endres M;Bassani VL;Koester LS; et al. Glioprotective effect of chitosancoated rosmarinic acid nanoemulsions against lipopolysaccharide-induced inflammation and oxidative stress in rat astrocyte primary cultures. Cell Mol Neurobiol, 2019.

12. Fachel FNS;Nemitz MC;Medeiros-Neves B;Veras KS;Bassani VL;Koester LS; et al. A novel, simplified and stability-indicating high-throughput ultra-fast liquid chromatography method for the determination of rosmarinic acid in nanoemulsions, porcine skin and nasal mucosa. J Chromatogr B, 2018,1083,233-41.

13. International Conference on Harmonization (ICH). Guidance for industry: Q2B validation of analytical procedures: methodology. 1996.

14. European Medicine Agency (EMA). Guideline on bioanalytical method validation 2012,1-2.

15. Food and Drug Administration (FDA). Guidance for Industry: Bioanalytical Method Validation. Cent Drug Eval Res, 2013,1-34.

16. Shabir GA. Validation of high-perfomance liquid chromatographic methods for the pharmaceutical analysis: Understanding the differences and similarities between the requirements of the US Food and Drug Administration, and the US Pharmacopeia and the International Con. J Chromatogr A, 2003,987,57-66.

17. Wang $\mathrm{H}$;Provan GJ;Helliwell K. Determination of rosmarinic acid and caffeic acid in aromatic herbs by HPLC. Food Chem, 2004,87,307-11.

18. Canelas V;da Costa CT. Quantitative HPLC analysis of Rosmarinic acid in extracts of Melissa officinalis and spectrophotometric measurement of their antioxidant activities. J Chem Educ, 2007,84,1502-4.

19. Modarres M;Asili J;Lahouti M;Gangali A;Iranshahy 
M;Sahebkar A. Simultaneous determination of rosmarinic acid, salvianolic acid b and caffeic acid in Salvia leriifolia Benth. root, leaf and callus extracts using a Highperformance Liquid Chromatography with diode-array detection technique. J Liq Chromatogr Relat Technol, 2014,37,1721-30.

20. Adham AN. Comparative extraction methods , phytochemical constituents, fluorescence analysis and HPLC validation of rosmarinic acid content in Mentha piperita , Mentha longifolia and Osimum basilicum. J Pharmacogn Phytochem, 2015,3,130-9.

21. Carocho M;Barros L;Calhelha RC;Ćirić A;Soković M;Santos-Buelga C; et al. Melissa officinalis L. decoctions as functional beverages: a bioactive approach and chemical characterization. Food Funct, 2015.

22. Jirovský D;Kosina P;Myslínová M;Stýskala J;Ulrichová J;Šimánek V. HPLC analysis of rosmarinic acid in feed enriched with aerial parts of Prunella vulgaris and its metabolites in pig plasma using dual-channel coulometric detection. J Agric Food Chem, 2007,55,7631-7.

23. Achamlale S;Rezzonico B;Grignon-Dubois $\mathrm{M}$. Rosmarinic acid from beach waste: Isolation and HPLC quantification in Zostera detritus from Arcachon lagoon. Food Chem, 2009,113,878-83.

24. Agência Nacional de Vigilância Sanitária. Farmacopeia Brasileira. vol. 1. 2010.

25. Couto RO;Conceição EC;Chaul LT;Oliveira EMS;Alves SF;Rezende KR; et al. Validated HPLC-PDA method for rosmarinic acid quantification in rosemary. Lat Am J Pharm, 2011,30,1951-6.

26. Öztürk N;Tunçel M;Uysal UD;Oncu-Kaya EM;Koyuncu O. Determination of Rosmarinic Acid by HighPerformance Liquid Chromatography and Its Application to Certain Salvia Species and Rosemary. Food Anal Methods, 2011,4,300-6.

27. Gudzenko A. Development and validation of a method for the determination of rosmarinic acid in Mentha piperita $\mathrm{L}$ - using solid-phase extraction and RP-HPLC with photodiode array detection. J Chem Pharm Res, 2013,5,40-5.

28. De Oliveira KB;De Oliveira BH. A HPLC/DAD
Determination of rosmarinic acid in Salvia officinalis: Sample preparation optimization by factorial design. Artic J Braz Chem Soc, 2013,24,85-91.

29. Liu J;Wan Y;Zhao Z;Chen H. Determination of the content of rosmarinic acid by HPLC and analytical comparison of volatile constituents by GC-MS in different parts of Perilla frutescens (L.) Britt. Chem Cent J, 2013,7,61.

30. Li X;Yu C;Sun W;Liu G;Jia J;Wang Y. Simultaneous determination of magnesium lithospermate $\mathrm{B}$, rosmarinic acid, and lithospermic acid in beagle dog serum by liquid chromatography/tandem mass spectrometry. Rapid Commun Mass Spectrom, 2004,18,2878-82.

31. Stelmakienè A;Ramanauskienė K;Briedis V. Release of rosmarinic acid from semisolid formulations and its penetration through human skin ex vivo. Acta Pharm, 2015,65 .

32. Zheng L;Gong Z;Lu Y;Xie Y;Huang Y;Liu Y;et al. A UPLC-MS/MS method for simultaneous determination of danshensu, protocatechuic aldehyde, rosmarinic acid, and ligustrazine in rat plasma, and its application to pharmacokinetic studies of Shenxiong glucose injection in rats. J Chromatogr B Anal Technol Biomed Life Sci, 2015,997,210-7.

33. Niessen WMA;Manini P;Andreoli R. Matrix effects in quantitative pesticide analysis using liquid chromatography-mass spectrometry. Mass Spectrom Rev, 2006,25,881-99.

34. Nemitz MC;Yatsu FKJ;Bidone J;Koester LS;Bassani VL;Garcia C V.;et al. A versatile, stability-indicating and high-throughput ultra-fast liquid chromatography method for the determination of isoflavone aglycones in soybeans, topical formulations, and permeation assays. Talanta, 2015,134,183-93.

35. Watanabe E;Kobara Y;Baba K;Eun H. Aqueous acetonitrile extraction for pesticide residue analysis in agricultural products with HPLC-DAD. Food Chem, 2014,154,7-12. 